\title{
IT and Professionalism in Developing Countries
}

\author{
Focus on Africa
}

\author{
Moira de Roche \\ President: Computer Society South Africa, General Manager - Laragh Skills (Pty) \\ Ltd, moirad@laragh.com
}

\begin{abstract}
Most of Africa is focused on alleviating poverty and starvation, so IT practice does not enjoy the prominence in Africa. However, developing the IT Industry, and ensuring that practitioners are professional, will provide an industry that can create wealth. After a brief discussion on what is meant by professionalism, this paper will explore the issues relating to IT in Africa, especially South Africa, and why Africa is the "forgotten continent" from a global IT perspective. It explores professionalism skills frameworks, and how proven skills levels can help change this perspective. Finally, it provides recommendations for a way forward.
\end{abstract}

Keywords: Information Technology, IT, Professionalism, Skills frameworks, Africa, standards

\section{Introduction}

In researching this paper, the author found very little research on IT in Africa, other than how it relates to the Digital Divide, or so called E-Development. According to the World Bank, E-development has two possible connotations - the development of the ICT related aspects of society (e.g. bundling egovernment, ecivil society, e-business and ICT infrastructure development) and using ICT as a tool within a holistic approach to social and economic development. The development of the IT Industry per se is largely ignored.

This is in stark contrast to other developing countries such as India and China. For this reason, much of its contents are anecdotal or the authors own opinions.

As the author lives in South Africa, is very involved with the Computer Society, and has been in the IT Training industry for many years, the paper will mostly relate to the situation in South Africa. It is also the most advanced nation in subSaharan Africa, with a flourishing IT Industry. 


\subsection{Africa in perspective}

Let's look at some numbers.

Perhaps the most useful way of looking at Africa is to consider its population in contract to the rest of the world. Table 1 below shows the populations of the 5 most populous countries.

Table 1. Most populous countries (Source: Wikipedia)

\begin{tabular}{|l|r|c|}
\hline Country & Population & $\begin{array}{c}\text { Percentage of World } \\
\text { Population }\end{array}$ \\
\hline World & $6,671,226,000$ & $19,84 \%$ \\
\hline China & $1,323,436,000$ & $16,97 \%$ \\
\hline India & $1,131,982,000$ & $4,55 \%$ \\
\hline USA & $303,902,495$ & $3,47 \%$ \\
\hline Indonesia & $231,627,000$ & $2,80 \%$ \\
\hline Brazil & $186,576,380$ & \\
\hline
\end{tabular}

Table 2. Shows the total population of Africa.

Table 2 - Populations of Africa and some countries in Africa. (Source: Wikipedia)

\begin{tabular}{|l|c|r|r|}
\hline \multicolumn{1}{|c|}{ Country } & $\begin{array}{c}\text { Total } \\
\text { Population }\end{array}$ & $\begin{array}{c}\text { Percentage } \\
\text { of total }\end{array}$ & 22 countries listed \\
\hline Africa (53 countries) & $922,000,000$ & $13.82 \%$ & \\
\hline South Africa & $47,850,700$ & $0.72 \%$ & No 26 in world \\
\hline Nigeria & $148,093,000$ & $2.22 \%$ & No 8 in world \\
\hline
\end{tabular}

South Africa has the highest GDP in Africa (see below) and Nigeria the largest population, which is why they have been listed in the above table.

And what about Gross Domestic Product?

Richest 10 African Countries 2006: GDP Per Country

1. South Africa

2. Algeria

3. Nigeria

4. Morocco

5. Sudan

6. Tunisia

7. Ethiopia

8. Ghana

9. Angola

10. Democratic Rep. of Congo
$\$ 606.4$ billion in international\$ (up 8\% from 2005)

$\$ 262.2$ billion (up 8.5\%)

$\$ 181.8$ billion (up $10.2 \%$ )

$\$ 150.8$ billion (up $4.8 \%$ )

$\$ 98.8$ billion (up $11.2 \%$ )

$\$ 91.4$ billion (up 7.4\%)

$\$ 78.4$ billion (up $12 \%$ )

$\$ 59.4$ billion (up 9.1\%)

$\$ 53.9$ billion (up 24.3\%)

$\$ 50.4$ billion (up 9.7\%)

Out of 50 African nations, the top 10 countries above generated almost $40 \%$ of Africa's total GDP in 2006. Note that each experienced growth over the previous year. 


\subsection{ICT in Africa}

According to the World Bank, Information and Communications Technologies (ICT) have now become an integral part and key enabler of today's development agenda. There is a growing and increasingly sophisticated demand for the Bank's support in this area. The Bank's capacity to respond to this demand is a "fundamental test of the World Bank's relevance in the years ahead" according to Jemal-ud-din Kassum, EAP Regional Vice President, at the recent e-government workshop (www.worldbank.org).

So it is clear that ICT is very relevant in Africa for two major reasons:

- As an enabler to development of communities and access to resources, such as e-government

- ICT skills become a marketable resource to increase the earning potential of a country, and move the economy from a largely agricultural economy to a knowledge economy.

\subsubsection{SADC}

Nowhere is this sentiment better illustrated than in the following Declaration on Information and Communications Technology (ICT) the level of commitment by the Southern Africa Development Community (SADC) countries.

PREAMBLE We, the Heads of State or Government of: The Republic of Angola; The Republic of Botswana; The Democratic Republic of Congo; The Kingdom of Lesotho; The Republic of Malawi; The Republic of Mauritius; The Republic of Mozambique; The Republic of Namibia; The Republic of Seychelles; The Republic of South Africa; The Kingdom of Swaziland; The United Republic of Tanzania; The Republic of Zambia; The Republic of Zimbabwe;

RECOGNISING that the Southern African Development Community needs a coherent regional policy and strategy on Information and Communications Technology (hereinafter referred to as "ICT") that promotes sustainable economic development, technology and bridges the digital divide within the Region and the rest of the world;

CONVINCED that a pervasive, reliable and affordable information and communications infrastructure is the foundation upon which the Southern African Renaissance can be built and sustained;

RECALLING the priority accorded to the challenge of bridging the digital divide in the Millennium Declaration adopted by the Millennium Assembly and statements made in the G8 Summit in Okinawa and the Southern African Economic Summit, 2001;

NOTING the capacity limitations in the Region, in particular shortage of skilled ICT personnel, high cost of development of ICT infrastructure, slow progress 
towards the deregulation of the telecommunications sectors leading to monopolies, unaffordability of universal access due to high tariffs and internet charges, lack of economic commerce readiness, reluctance of acceptance for ICT culture and innovations;

CONCERNED about the lack of regional policy and strategy on ICT and the digital divide between and within countries and the Region, which have the potential to widen the socio-economic disparity that exists;

FURTHER NOTING that international experience has shown that ICT, if harnessed, can contribute significantly to the economic development of countries and facilitate the provision of a better life for citizens;

AWARE that the digital divide does not only manifest itself economically or technologically but also culturally, creating a world that is increasingly less representative and reflective of the languages, cultures, ideas and diversity of the peoples of the world;

RECALLING Decision 52/2000 of the SATCC Committee of Ministers which urged Member States to give ICT priority for national and regional socioeconomic development and accord such recognition in their national programmes in the effort of turning the Region into an information - based economy;

RECOGNISING that ICT is a fast, reliable, efficient and easy way of communication and information exchange;

ACKNOWLEDGING that effective information communication is best achieved under an environment characterised by:

- policy guidelines;

- legislation;

- well defined strategy;

- telecommunications deregulation;

- reliable, efficient and scalable network infrastructure;

- human resources development in the area of ICT;

- knowledge management;

- affordable access to information;

- natural way for collaboration and conversation;

- seamless integration;

- ubiquitous access; and

- security;

AWARE that the challenge for SADC is to ensure improved living standards for all its people, by harnessing the human, capital, technology and material resources at its disposal in the most productive and sustainable manner......, (Source www.sadc.int) 
So at government level, there is awareness and some commitment to building IT capacity on the continent, and the benefits of doing so, especially the opportunity to grow the economies. It should be noted that this goes far beyond the necessity to lessen the Digital Divide. Unfortunately, and perhaps necessarily, aid to the continent remains focused on poverty and disease alleviation. Whilst this is understandable, it creates an additional "divide" - what Africa needs to save itself, versus the world simply providing food and medicines, and not looking at longer term issues.

\section{IT Education and Skills in Africa}

In their paper Description of Computer Science Higher Education in Sub-Saharan Africa: Initial Explorations, Marshini Chetty et al, state " Many countries in SubSaharan Africa (SSA) are in need of technology innovators who are equipped to leverage technologies in locally relevant domains such as health, government and education. To create skilled graduates who can build and shape locally relevant technologies, higher education institutes in Africa must have Computer Science (CS) education programs that meet local needs, for example, to satisfy the demand for entrepreneurs to build industry and strengthen an economy".

The Universities in South Africa produce, for the most part, skilled and knowledgeable computer science graduates. However, business and industry often level the accusation that these graduates are not "what is needed by business". This might or might not be true: what is very evident is that there are several graduates (and other apparently experienced individuals), who do not easily find suitable employment, whilst at the same time there is a widely reported "skills shortage".

There are other surprising examples of Centers of Excellence: The Computer and Information Technology Department, Makerere University, Kampala, Uganda is widely acknowledged as one of these.

In addition, each year, South Africa produces 1,400 engineers with B.Eng. and B.Sc. Eng. degrees. Only about half of these graduates go on to register with the Engineering Council of South Africa (ECSA) as practicing professionals (and very few join Computer Society South Africa). The Joint Initiative on Priority Skills Acquisition (JIPSA - a South African initiative to develop scarce and priority skills) has determined that to meet projected demand, the average annual output of engineers from the higher education sector needs to increase by 1,000 to a total of 2,400 a year. Measures need to be put in place to ensure that these graduates become registered professionals. (JIPSA report).

At the same time, enrolments into Computer Science and Bachelor of Commerce degrees with Information Systems as a major have been steadily declining. The author believes this can be attributed to the following:

- Poor quality of mathematics and science education at school level.

- Few school leavers with these subjects at an acceptable grade. 
- No mechanisms for identifying talent in learners who don't have these subjects but still have an aptitude for Computer Science.

- Lack of understanding by learners (especially in poor communities) of what a career in IT involves.

- IT teachers are attracted to commerce, so there is a severe lack of Computer teachers at school level. The situation is worsening.

A Comptia report, developed by the Center for Strategy research, finds that:

- Companies in emerging markets report more skills gaps

- Emerging countries find all IT skills will increase in importance over the next five years and that their IT headcount will increase over this period.

This clearly illustrates that the emerging countries in Africa will need more and more IT practitioners, against a backdrop of reducing numbers of graduates.

In a report in ITWeb, a South African daily online publication, Harish Lala, country manager of ZenSar Technologies, says that while the local market is growing, SA stands on the back foot in the offshoring business. He says skillsmore than other economic factors like the credit crunch and electricity crisis - is SA's biggest challenge. He goes on to say that SA is competing with markets in Eastern Europe, the Far East and South Asia to capture and retain business. "These countries are moving swiftly to develop skills, and Europe and the US are looking at the best options they can get. The reality is that skills (in SA) need to be developed at a faster rate than they are currently."

Jay Reddy, Managing Director at Dimension Data KZN, adds weight to the skills shortage argument, saying they have had to contract specialists from a sister company in India. Reddy said the increased demand for networking infrastructure skills across Africa has fuelled the demand for high calibre people. "From our perspective there are very few high end networking skills particularly around the Cisco networking technologies which require high end routing and advanced switching skills. The same goes for telephony and wireless skills in the massively growing IP sector." Reddy goes on to say that the gap is at least $60-70 \%$ or more. For every 10 vacancies only about 3 or 4 people would have the requisite skills. Mr Reddy points out that while SA does have learnership and graduate programmes to incorporate more skills, there is a big gap in output from tertiary institutions. "Tertiary institutions appear to focus their degree courses more on Business Analysis and programming techniques, with very little emphasis spent on networking and voice technologies within the IP space. Networking and voice, particularly in the IP space, is complex and requires sound theoretical knowledge of the IP Protocol to enable a candidate to grasp the concept and excel therein."

Mr Reddy's comments put a different spin on the skills shortage issue, which is often thought to be only in the software development arena. Learnership

${ }^{1}$ Source: "Skills forum to focus on high end networking skills" www.smartxchange.co.za 
programmes develop entry level skills, but the shortage lies in high-end skills in both software development and networking.

It should also be noted that there is an ongoing discussion on the difference between software development, and software engineering, with the majority of people using the terms interchangeably.

Furthermore, industry qualifications such as those offered by Cisco and Microsoft have enjoyed huge success in South Africa. It is possible that their popularity has been counterproductive in that several school leavers saw these certifications as an alternative to a degree or diploma, rather than as a means to enhance skills for those already in the workplace. At one stage (about six or seven years ago), South Africa had more Microsoft Certified Systems Engineers (MCSE's) than the United Kingdom!

\section{ICT Hubs}

Mauritius, an Indian Ocean Island off the East Coast of Africa, experienced a reduction of the GDP as a result of their two main crops, Cotton and Sugar, being produced more competitively elsewhere in the world. The government made a policy decision to develop towards becoming an ICT Hub. The government established the National Computer Board. In view of promoting Mauritius as a competitive location for ICT activities, marketing the Mauritian ICT industry abroad and assisting local operators with establishing contacts and partnerships with potential customers, joint venture partners and outsourcers, the NCB regularly participates in international events, such as the Salon Européen des Centres des Contacts et de la Relation Client (SECA) held in Paris each year, and proposes to participate in other fairs like the Birmingham Call Centre Expo in the UK , the Bangalore IT Fair, EBIT in Madagascar, Cyber in Reunion Island and COMDEX in South Africa. (source www.gov.mu). There are incentives for companies to provide training on ICT related subjects. And pay rates are fairly low when compared to developed countries (and even South Africa), so with continual marketing, and proof that their IT practitioners meet a minimum standard, combined with quality outputs, should provide the opportunity for Mauritius to compete globally.

South Africa has three organizations whose purpose is to create an ICT Hub in their respective regions: Innovation Hub in Gauteng Province; SmartXchange in Kwazulu-Natal (KZN); and Cape IT Initiative in Western Cape. Each one of these has a slightly different vision and goal:

Innovation Hub - A community of pioneers, inventors, entrepreneurs and free thinkers - challenged and inspired, breaking new ground, collaborating and inventing new technologies.

The Cape IT Initiative (CITI) is a networking and cluster development agency that brings together people, ideas and capital to grow the Western Cape, South 
Africa's ICT sector. CITI's goal is to promote Cape Town as a global IT hub and gateway into Africa, thus facilitating the creation of jobs and prosperity through IT.

The Core Mandate for SmartXchange includes: Developing a quality ICT SMME base in KZN (Incubation and SMME support); Cluster Development and Promoting the region as an ICT hub of Africa; ICT Skills Development; and Supporting initiatives that work to bridge the digital divide

\section{IT Professionalism in Africa - with emphasis on South Africa}

We have the skills, but not in the numbers needed. Also, Africa has long been an exporter of raw materials, without beneficiation, and this culture persists in our thinking. Innovation is still a scarce commodity, although we have some amazing examples of world class technologies being developed, the most well-known of which is probably Mark Shuttleworth, who sold the digital encryption technology for millions of dollars.

According to the ICT Census commissioned by Cape IT Initiative in 2007, IT consultancy is the "product" most regularly exported, and the greatest percentage of IT exports are to elsewhere in Africa. This is encouraged, as Africa is an open market, less affected by the IT prominence of the Asian tigers than Europe or North America, but we need to become a global player.

So what can we do to improve our status as a center for excellence in IT? The author believes that finding a mechanism to confer an internationally recognized professional qualification on IT practitioners would be a firm step in the right direction.

There is often some confusion about what professional groups exist in IT. Peter J. Denning 2, writing for an ACM publication states that there are over 40 organized groups in computing and information technology. IT-specific disciplines are the core technologies of computer science and engineering, and include; Computer Science, Software Engineering, Operating Systems, to name only a few. ITIntensive disciplines are the other branches of science, engineering and commerce that innovate in IT as part of their work. Examples include: Aerospace engineering; Banking and financial services; and Telecommunications. The third group - IT-supportive occupations - are relatively new professional specialties that support and maintain IT Infrastructure. They include Help Desk technicians, Web Masters, IT trainers.

What do we mean by Professionalism in IT? Charles Hughes, past President of British Computer Society, and Chairman of the IP3 Task Force, in his paper "Characteristics of a the profession and IT Professionals" states that "A profession is a vocation or pursuit, especially one which involves some branch of advanced learning, and the body of people engaged in it.

2 “When IT Becomes a Profession” Peter J Denning, 2001 
(Furthermore), a profession must:

- be a community controlled by regulation or by a governing body/bodies (most usually

- professional institutions or associations) which directs the behaviour of members of the

- community in professional matters

- determine the knowledge, skills, attributes and experience required by professionals

- give leadership and deliver on its promise to the public it serves in its specific field of activity

- adhere to the general standards of professional communities and define those attributes and

- characteristics that distinguish a specific profession from others

- be valued for its contribution to society

The definition of a professional adopted by the British Computer Society Professionalism in IT programme is:

A fully established IT professional is a practitioner who has specific skills rooted in a broad base and appropriate qualifications, belongs to a regulated body, undergoes continuous development, operates to a code of conduct and recognises personal accountability.

Although Computer Society South Africa (CSSA) has had a Professional grade of membership for some years, they have only recently implemented a professional qualification. The Computer Professional Education qualification was developed in Australia by the Australian Computer Society ACS. The learning materials are provided online, so they can be accessed from anywhere. The qualification is aimed at practitioners with a bachelor level degree, and at least 18 months' working experience. Recognition of prior learning procedures are in place for those who have experience or other studies that are deemed equivalent to a $\mathrm{B}$ degree.

The IP3 Task Force, set up by IFIP, started its work in January 2007. The Task Force is working towards creating an International Professional Practice Programme. This is global programme led by IFIP (The International Federation for Information Processing) to promote professionalism in IT, define international standards and create a global infrastructure that will encourage and support the development of both practitioners and employer organizations and give recognition to those who meet and maintain the required standards for knowledge, experience, competence and integrity.

IP3 certification schemes, of which the first will be the 'gold standard' International IT Professional (IITP) certification will be:

- Vendor independent

- Operated by accredited IFIP member bodies

- Available worldwide 
- Based on consistent global standards for professionals in all areas of IT activity

- Built around a requirement for complete professional formation - including relevant knowledge, experience, competence and commitment to a code of professional ethics

- Dependent on the maintenance of competence through a programme of continuing professional education and development

- Supported by a disciplinary code with a process for public complaint and sanctions where appropriate.

Within this overall independent framework IP3 certification schemes will recognize and give credit to other certification schemes, including vendor certification, wherever these provide appropriate and valuable assurance for part of the overall professional formation. ${ }^{3}$

For developing countries in Africa, such a programme will have significant benefits; the most important of all is "guaranteeing" the standard of IT professionals who have received the qualification. So "where you come from" will be less important than the professional qualification you hold.

Other benefits include:

For the Practitioner

- increased recognition and reward - IT staff at all levels often feel they are undervalued

- greater mobility - people should be able to work where they want to, and not be disadvantaged because of where they come from

- career path - professional practitioners will increase their opportunity to reach clevel positions in their organizations

- professional accountability - as with other professions, IT practitioners should have a sense of accountability for the success and quality of the work they are engaged in

- Be part of a global community of professional practitioners

\section{For Employers}

- improved risk management and corporate governance

- more successful IT enabled business change

- enhanced recruitment and talent management

- global companies can be assured that all internationally qualified staff meet a minimum professional standard, thus enabling a mobile and agile workforce.

It is hoped that South Africa will lead the way in providing a qualification that will be accredited by the international body. The model we are using - using the ACS qualification, is easily replicable and transportable. We can modify the learning materials at a later stage if deemed necessary: however, we find that the

${ }^{3}$ IP3 - Building an International Professional Practice Programme, Colin Thompson, IP3 Task Force 
materials are not country specific as they have been designed for a global audience.

IP3 has a long term goal to, with assistance and guidance from IFIP, SADC and the African Union, and mentoring from Computer Society South Africa, Australian and other member Societies, to roll-out a qualification which meets the standards to other countries in Africa.

The Skills Framework for the Information Age (SFIA) is the high level UK Government backed competency framework describing the roles within IT and the skills needed to fulfil themSFIA is the widely used two-dimensional IT skills framework, which is made available at no cost to the end user (www.sfia.org).

It is envisaged that a recognized professional in IT will:

- belong to a recognized, regulated professional community for information and communications technology workers

- share with other professionals the understanding of a core body of knowledge (CBOK)

- have knowledge of one or more specialist area

- demonstrate the capability to operate at the equivalent of SFIA Level 5 or above

\section{Recommendations}

IT has much to offer Africa, in terms of economic development. We have to ensure that we are not left behind, or perceived as lacking in the requisite IT skills.

It is therefore essential that African Computer Societies, and relevant government departments throughout the region work towards setting up skills frameworks, based on SFIA (adapted rather than reinvented). We must also implement a professional standard and qualification that is mandated or chartered by the government.

IP3, together with IFIP, and Societies that already have a professional qualification, should engage with African Societies - where they exist - and government departments to share best practice, and actively assist them with becoming professional bodies with a relevant qualification. IFIP and IP3 must:

- Use forums and conferences such as WITFOR to get the message out to emerging African countries.

- IFIP, in partnership with CSSA, should continue in its quest to set up an African consortium. This has been in the plans for some years now, but funding is essential to its ongoing success.

- Find early adopters for the IP3 programme in Africa. Computer Society South Africa is already on its way, and Botswana and Ethiopia have expressed interest.

- - IFIP must assist African Societies in ensuring the elements of professional practice are embedded in their constitutions: an enforced code of conduct, ethics, responsibility; suitably stringent entry requirements for professional membership,

- Africa must use and adapt existing frameworks, and resist the urge to create their own. 
- Using an online offering, such as that offered by the ACS CPE, is highly recommended for the following reasons:

1. It can be adopted in a short space of time

2. There is no need to recreate infrastructure

3. The standards of delivery are consistent

4. Candidates can interact with practitioners around the world, sharing best practice, and thus are not constrained by the boundaries of their own country.

5. Regional societies can provide mentoring - with the possibility of creating a revenue stream.

- Encourage aid monies and skills toward this end.

From an IT perspective, Africa does not have to stand in anyone's shadow. We are capable of playing on the world stage, and must to do because IT can be true creator of wealth. 